critérios para a seleção de uma estratégia de treinamento.

Parte 3: Desenvolve as questões relativas à alocação e arranjo de recursos para aprendizagem. Aqui são tratados três temas básicos: a) recursos disponíveis a um treinador-administrador; b) papéis que os treinadores podem praticar numa situação de aprendizagem; c) relações entre treinadores e treinandos e as estratégias disponíveis.

Parte 4: Trata de avaliação da eficácia do treinamento, considerando: a) o papel da avaliação; b) a natureza das inter-relações que existem entre objetivos, métodos de ensino e as várias estratégias de avaliação; c) considerações técnicas tais como fidedignidade e validade, e as diferenças entre critérios e testes de referências normalizadas; d) as diferenças técnicas de avaliação que podem ser usadas para determinar se os objetivos cognitivos, afetivos e psicomotores foram atingidos com pleno sucesso; e) como a eficácia de um programa de aprendizagem pode ser avaliada.

A obra traz informações acerca da visão moderna do treinamento. Aborda, sem dúvida alguma, as relações entre objetivo, técnica de ensino e método de avaliação, estabelecendo a sua independência em relação ao tipo de treinamento desejado.

Luís César G. de Araújo

\section{A organização humana}

Por Rensis Likert. 1.a ed. São Paulo, Editora Atlas, 1975.

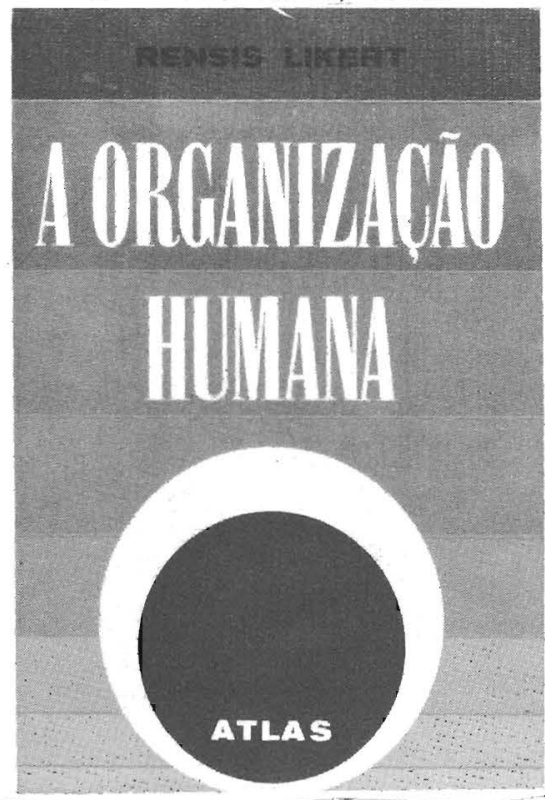

Baseado em estudos rigorosos do Instituto de Pesquisa Social de Michigan, Rensis Likert descreve um sistema de administração científica, ou mais precisamente um modelo que, de acordo com o comportamento das variáveis, passa a ser denominado de sistema 1, 2, 3 ou 4, num gradiente.

As variáveis organizacionais do modelo referem-se à natureza: a) da liderança aplicada; b) das forças motivacionais; c) do processo de comunicação; d) do processo decisório; e) do processo de influência e interação; f) do sistema de metas e diretrizes; g) do processo de controle.

Os resultados da pesquisa quantitativa revelam que as empresas mais eficientes aproximamam-se do sistema 4 (quatro). Enquanto que as menos eficientes tendem para o sistema 1 (um), que se caracteriza por uma administração hierarquicamente controlada. Já o sistema 4 (quatro) é de administração participativa, e tem como conceitos básicos 'o "relacionamento de apoio", a "tomada de decisão em grupo", o "método grupal de supervisão" e a "fixação de elevado padrão de desempenho individual".

$\mathrm{O}$ autor sustenta que, conforme as pesquisas, à medida que os métodos de administração tendem para o sistema 4 (quatro) há benefícios em termos de produtividade, custos e atitudes dos empregados. De modo inverso, à proporção que a administração inclina-se para o sistema 1 (um) a produtividade tende a baixar, os custos a elevarem-se e as atitudes dos funcionários são menos produtivas.

Centenas de administradores de diversas áreas - produção, vendas, finanças, escritório, etc. - reconheceram, por meio de questionários, quais os meIhores métodos de administração (sistema 4), porém tais métodos não eram os mesmos que eles aplicavam em suas respectivas unidades de trabalho. Likert procura, então, lançar luzes à indagação: "Por que os administradores utilizam um sistema administrativo que eles próprios reconhecem ser menos eficiente que outro por eles mesmos descrito como mais eficiente?"

Pelas características do sistema 4 (quatro) infere-se que ele, mais que qualquer outro sistema, exige melhor preparo técnico dos administradores. Basicamente, maior conhecimento sobre a natureza das organizações e sobre as forças que motivam o trabalho humano. Como salienta Likert, a competência, motivação e eficiência da organização humana determina a própria empresa. Daí, dirigir o componente humano é a tarefa administrativa crucial.

Como mudar para o sistema 4 (quatro) de administração? 0 autor apresenta um roteiro nesse sentido, cujo ponto fundamental reside em três categorias de variáveis: "causais", "intermediárias" e "de resultado". Para se aprimorarem, as empresas devem concentrar-se nas va- 
riáveis causais, pois são elas que determinam o curso dos eventos e os próprios resultados organizacionais. No capítulo 8 as variáveis são amplamente discutidas quanto à natureza e relacionamento entre si, e em termos de como são tratadas pelos sistemas 2 (dois) e 4 (quatro). Também no apêndice o autor apresenta - classificadas nas três categorias citadas - um grande elenco de variáveis organizacionais.

Merecem destaque as decisões que são tomadas sem considerar, adequadamente, o componente humano. A deficiência do processo estaria no sistema contábil que não registra os ativos intangíveis. Likert propõe e discute a mensuração desses ativos. Afirma que hodiernamente “já é possível aferir o valor corrente da organização humana de uma firma e da satisfação de sua clientela". É necessário que os administradores tenham idéia do valor da organização humana (e das tendências desse valor) de suas empresas, porque "a lucratividade e a sobrevivência a longo prazo da empresa dependerão muito de decisões corretas, inspiradas por mensurações que reflitam o valor corrente da sua organização humana".

A organização humana é o primeiro livro de uma trilogia. "O segundo volume descreverá em minúcias o sistema de administração científica derivado dos princípios e práticas dos administradores mais bem sucedidos". O último "examinará as experiências que se realizam visando fazer com que número cada vez maior de empresas passe a adotar a administração científica" nos moldes do sistema 4, relatando sobre as estratégias de mudança e sobre como assimilar as aptidões necessárias às funções empresariais.

Conquant? Likert destine esse livro "aos interessados em aplicar os resultados da pesquisa quantitativa no aprimoramento da administração dos recursos humanos", cremos que, pela sua coerência e aplicabilidade, o livro tem destinação bem mais ampla.

Marcos Antonio Frota

\section{REEMBOLSO POSTAL}

\section{OBSERVACAO IMPORTANTE}

A fim de simplificar e tornar mais rápido o envio de pedidos de publicações da Fundação Getulio Vargas, sugerimos o uso do reembolso postal, que beneficiará principalmente às pessoas residentes em locais afastados dos grandes centros. Assim, na ausência, em sua cidade, de representantes credenciados ou livrarias especializadas, dirija-se diretamente pelo reembolso à

\section{EDITORA DA FGV \\ PRAIA DE BOTAFOGO 188 \\ CAIXA POSTAL 9052 - ZC-02 \\ RIO DE JANEIRO}

RIO DE JANEIRO 